\title{
NOTES ON THE ANALYSIS OF ZINC ORES.
}

\author{
By E. Waller, Ph. D.
}

The time at my disposal for these experiments has been limited, and has constantly been broken in upon, so that what is presented will, I trust, be regarded with indulgence; more as a sketchy account of experiments on this subject than as a thorough investigation.

The object was to attempt to find or to invent a convenient and fairly rapid method of general applicability for the determination of zinc in its ores. Experiments were first made with Schneider's method. A Franklinite ore containing copper, and said to contain about 30 per cent. of zinc, was used. Schneider's method (Ztschr. anal. Chem., 23, 562), may be thus sketched. Treat $1 \mathrm{gm}$. of ore with 10 c.c. conc. sulphuric acid, together with 1 or 2 c.c. conc. nitric, heat until strong fumes of $\mathrm{SO}_{3}$ appear; dilute carefully with 70 c.c. of water, pass sulphuretted hydrogen for 15 minutes through the hot solution, heat to boiling, filter and wash until a volume of about 200 c.c. is obtained, add ammonia to the solution (heated) until a slight cloud persists, bring this into slear solution by addition of a few drops of sulphuric acid, dilute to 500 to 600 c.c., and pass $\mathrm{H}_{2} \mathrm{~S}$ for an hour. Under these conditions Schneider states that zinc only is precipitated.

Some difficulties manifested themselves in applying this method to the ore selected. However finely pulverized, the decomposition of the Franklinite appeared incomplete. Diluting with 70 c.c. of water seemed to be insufficient, a small amount of the copper remaining in solution and appearing with the zinc; when the stage of separation of the zinc was reached, passing sulphuretted hydrogen for one hour, was found to be too short a time for complete separation. The precipitate also was not in a condition that permitted of its being readily filtered and washed. It also 
appeared colored, and some phenomena gave rise to a suspicion that it contained manganese as well as copper, but through inadvertence, tests were not made for Mn. The percentage of zinc obtained by this method was from 25 to 25.4 . If the ore was really 30 per cent., fire per cent. had been lost.

With the expectation of decomposing the ore more completely at the start, a portion of the ore was first heated with hydrchloric acid (about 10 c.c.) and then sulphuric and nitric acid added, and Schneider's method followed through as before. The decomposition of the ore was apparently complete both from the appearance of the insoluble residne, and the percentage of zinc obtained (30.03 and 29.92), but the plan had its objections both as to the time and the attention it required. Hydrochloric acid caused the separation of gelatinous silica, which retarded the action of the acids, and in driving out the $\mathrm{HCl}$ afterward by heating with $\mathrm{H}_{2} \mathrm{SO}_{4}$, at a certain stage the solution bumped violently, and required constant attention.

The addition of hydrochloric acid at the same time with the other acias, carrying the rest of the process through as before, seemed to have all the disadvantages of the preceding experiment, without any gain in the completeness of decomposition of the ore. The percentage of zine found was as before, about 25 .

With a view to effecting a more complete separation of the copper, the solution after the first dilution (with $\% 0$ c.c. of water), was cooled before passing sulphureted hydrogen. The last traces of copper were, however, not thus removed. The proportion of copper present in the ore was small, however (probably 0.2 per cent.), or at any rate less than 0.5 .

A solution containing most of the zinc in the ore, and the other constituents excepting copper and silica, was then made, and experiments made as to the separation of the zinc without a prelim. inary removal of the iron, manganese, etc.

Ribau's method (Bull. Soc. Chim., 50, 518) was followed on one portion, as prescribed by him. Sodium carbonate was added until a faint permanent turbidity was produced, a few drops of hydrochloric acid were then added to clear the solution, then an excess 
of sodium hyphosulphite, and the solution was diluted until it contained less than $0.1 \mathrm{gm}$. of zinc per 100 c.c. Sulphuretted hydrogen was then passed through, in the cold. The precipitate, instead of being pure, white zinc sulphate as described by Ribau, was dark gray, being evidently contaminated with iron. Variations in the proportion of hyposulphite, or in the degree of dilution, had no effect in preventing completely this contamination of the precipitate, so far as could be seen. Zimmerman's suggestion (Chem. News, 40, 273), to neutralize the solution, add an excess of ammonium sulphocyanate, and precipitate by sulphureted hydrogen, warming the solution, gave the most satisfactory results as to rapidity of separation of the precipitate, its purity and its granular condition, allowing of ready filtering and washing. With some other zinc ores, however, it did not seem to work so well, but experiments remain yet to be made as to the cause of this difference of action, cumpleteness of precipitation, etc.

The partial success with this last suggested a trial of the method recommended by Moore for the separation of zinc and nickel by means of $\mathrm{KCy}$ and ammonium sulphide (Chem. News, 49, 151). The precipitate proved to be very slimy, and contained prussian blue, and for these and other reasons experiments in this direction were abandoned.

Bragard's method (Ztschr. anal. Chem., 27, 209) of precipitation with sulphureted hydrogen in a solution containing formic acid was tried, but thus far with poor success. The proper ratio between the amounts of formic acid, of the metals present, etc., was probably not obtained.

On that method it will be necessary to make more experiments. The separation of the precipitate was very slow and unsatisfactory.

Incidentally $I$ have been led to investigate the properties of zinc ammonium phosphate as a means for determining zinc.* A few notes on the results may be of interest :

Solutions of pure metallic zinc in hydrochloric and sulphrisc acid were used. A solution of microcosmic salt was used as the

Stone, Jour. Am. Chem. Soc., 4, 26. Tamm, Ztschr. anal. Chem., 13, 320. Bragard, $i b ., 27,212$. Lose Kam and Meyer, $i b ., 96,78$. 
reagent. A sufficient excess of the reagent was added, then ammonia until it was in excess, and then the solution (usually about 200 c.c.), was heated for an hour or more, until all odor of ammonia was gone, and the precipitate had assumed a crystalline character. The bumping of the solution on attempting to boil was so troublesome, that the plan of immersing the beaker in boiling water was adopted. The persistent adherence of portions of the precipitate to the wides of the beaker was another source of annoyance. This difficulty was avoided by washing thoroughly by decantation, and then dissolving in as little nitric acid as possible, running the solution through the filter paper into a weighed platinum dish, svaporating and then gradually heating up to the temperature of ignition. A too hasty application of the heat, or incineration of the precipitate in the filter paper, invariably caused a loss. After being once ignited to $\mathrm{Zn}_{2} \mathrm{P}_{2} \mathrm{O}_{7}$, further ignition had no appreciable effect, nor was there any loss when pieces of filter paper were laid over the precipitate in the crucible and the whole heated until the paper was destroyed. "The precipitate always sintered together under the influence of the temperature of ignition, and sometimes, without apparently having been heated any longer or to any higher degree, it fused to a vitrious mass.

$0.511 \mathrm{grm}$. of the precipitate after drying at $110^{\circ}$ to constant weight, weighed $0.4365 \mathrm{grm}$. after ignition. Assuming the dried precipitate to be $\mathrm{ZnNH}_{4} \mathrm{PO}_{4} 0.511$ grm. should yield 0.43636 grrn. of $\mathrm{Zn}_{2} \mathrm{P}_{2} \mathrm{O}_{7}$.

The precipitate is quite soluble in ammonia, the solubility increasing rapidly with an increase of temperature.

Ammonium chloride and oxalate acted in the same way. From the ammonium chloride solutions, where they had been used hot, considerable quantities of the precipitate separated on cooling, but it was found that when 15 to $18 \mathrm{grms}$. or more of $\mathrm{NH}_{4} \mathrm{Cl}$ were present in 200 c.c. of liquid, the results were too low though the solutions were kept cold, but with smaller proportions of $\mathrm{NH}_{4} \mathrm{Cl}$ (5 to 8 grms.), the results were fairiy good, with cold solutions.

Much larger quantities of microcosmic salt, of ammonium ni- 
trate or of ammonium sulphate, had much less of a solvent effect. In the cold they dissolved apparently nothing appreciable. At some future day I hope to be able to report more complete results and conclusions on these subjects.

\section{ABSTRACTS: ANALYTICAL CHEMISTRY.}

Determination of Tungsten in Tungsten Alloys. Dr. Jos. Preusser.

Place .5-1 grm. of the finely pulverized alloy in a porcelain dish, and roast the alloy until it has assumed a pure yellow color, showing that the tungsten has been oxidized to tungstic acid. Rinse the mass into a porcelain evaporating dish, add nitro-hydrochloric acid and evaporate; continue the evaporation several times after addition of hydrochloric acid and finally dry at $120^{\circ} \mathrm{C}$. Jigest with dilute $\mathrm{HCl}$ for several hours and filter. Ignite the residum (tungstic acid and silica) in a platinum crucible; mix intimately with 3-4 times its weight of sodium carbonate, and fuse for $\frac{1}{2}$ hour. Cool, dissolve in water, and filter. Treat any residuum again with sodium carbonate as before. The combined alkaline filtrates containing the tungstic and silicic acids are super-saturated with $\mathrm{HCl}$ and evaporated. The residue should be several times evaporated to dryness after additions of $\mathrm{HOl}$. Transfer the residue to an Erlenmayer flask, removing any adherent matter from the porcelain dish by means of ammonium hydrate. Add excess of ammonia and heat gently, and finally filter, collecting the filtrate in a weighed porcelain dish. Evaporate to dryness and ignite to constant weight. The resulting produet is tungstic acid. Much time is saved by the above method. (Ztschr. anal. Chem., 28, 173.) J. F. G.

\section{Determination of Phosphoric Acid in Sweet Wines. W. Fresenius.}

In determining $\mathrm{P}_{2} \mathrm{O}_{5}$ direct in the ash of wines very rich in saccharine matter, considerable $\mathrm{P}_{2} \mathrm{O}_{6}$ may be lost. It is advisable to remove the alcohol by evaporation, and then ferment the 